\title{
REFERENCE RESOLUTION USING SEMANTIC PATTERNS IN JAPANESE NEWSPAPER, ARTICLES
}

\author{
Takahiro Wakao \\ University of Shefficld, 1)epartenent of Computer Science \\ Regent Court, 211 Portobello St, Sheffield SL 4DP, UK \\ Email: t.wakao@des.shef.ac.uk
}

\section{INTRODUC'TION}

Reference resolution is one of the important tasks in natural language processing. In Japanese newspaper articles, pronouns are not olten used as referential expressions for company names, but shortened company names and dousha ("the same company") are used more often (Muraki ol al. 1993). Although there have boen studies of reference resolution for various noun phrases in Japanese (Shibala el al. 1990); Kilani 1994), except Kitani's work, they do not clearly show how to find the referents in computationally plausible ways for a large amount of data, such as a newspaper database. In this pajer ${ }^{1}$, we detemine the referents of dousha and their locations by hand, and then propose one simple and two heuristic methods which use scmantic information in text such as company nantes and their pattens, so as to test these three methods on how accurately they find the correct referents.

Dousha is found with several particles such as "ha", "gl", "no", and "lo" in newspaper articles. Those which co-occur wilh ha and ga are chosen for the data since they are the two most frequent particles when dousha is in the subject position in a sentence. 'l'ypically, ha marks the topic of the sentence and ga marks the subject of the sentence. A typical use of dousha is as follows:

Nihon Kentakii Furaido Chikin ha, Japan Kentucky liriol Clacken ha,

sekai saidai no pira chien,

world's largest pizar chain store,

P'iza liatio to teikei wo numsubi,

Jizaa flut to tic-up establish,

kotoshi gogatsu kala zenkoku do

starting May this year, nation-wide,

takuhai piza chien no tenkai wo

pizza delivery chain store extension

\footnotetext{
1'This paper was written when the anthor was at the Computing Iensearch labomatory of Ne:w Mexico Stide: University.

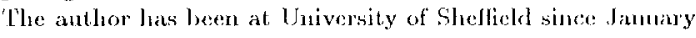
199.4.
}

hajinesu to happyou shita.

begin amnounced.

sarani dousha ha furaido chikin no Moreover, the same company fricd chicken of

takuhai saabisu nimo noridasu.

delivery service as well will start.

$\Lambda$ rough transiation is:

"Kentucky Fried Chicken Japan announced that it hat established a tie-up witl the world largest pizar chain store, Pizha Hut, and began to expand piza delivery chain stores nation-wide starting in May this year. Morcover, the company will start delivery of fried chicken as well."

Dousha in the second sentence refers to Kenlucky lined Chicken Japan as "the company" does in the linglish translation. As shown in this example, some articles contain more than one possible referent or company, and the reference resolution of dousha should iclentify the referent correctly.

\section{LOCATIONS AND CONTEXTS OF' 'THE REREREN'TS}

Most of the Japanese newspaper articles examined in this study are in the domain of Joint-Ventures. The sources of the newspaper articles are mostly the Nikke and the Ashahi. 'The total number of the articles is 1375, and there are 42 cases of dousha with ga and 66 eases of dousha wilh ha in the entire set of articles.

The following tables, Table 1 and Table 2, show the locations and contexts where the referents of both subsets of dousha appear. 
Table 1 Locations and contexts of the referents of dousha with ga

\begin{tabular}{|c|c|c|}
\hline \multicolumn{3}{|c|}{ doush $a$ with $g a$} \\
\hline location & context & number of cases \\
\hline \multicolumn{2}{|c|}{ Within the same sentence } & 19 \\
\hline Subject & company name + ha & $\overline{7}$ \\
\hline & part of the subject $*$ & 1 \\
\hline Non-subject & company name + niyoruto & 3 \\
\hline & others $* * *$ & 8 \\
\hline \multicolumn{2}{|c|}{ In the previous sentence } & 13 \\
\hline Subject & company name $+h a$ & 8 \\
\hline & company name + ga & 1 \\
\hline & emphasis structure ** & 1 \\
\hline & part of the subject $*$ & 1 \\
\hline Non-subject & company name + to & 2 \\
\hline \multicolumn{2}{|c|}{ In two sentences before } & 6 \\
\hline Subject & company name + ha & 5 \\
\hline & company name $+g a$ & 1 \\
\hline \multicolumn{2}{|c|}{ In previous paragraph } & 1 \\
\hline Topic of the paragraph & company name $+h a$ & 1 \\
\hline \multicolumn{2}{|c|}{ In two paragraphs before } & 3 \\
\hline Topic of the paragraph & company name $+h a$ & 3 \\
\hline
\end{tabular}

Table 2 Locations and contexts of the referents of dousha with ha

\begin{tabular}{|c|c|c|}
\hline \multicolumn{3}{|c|}{ dousha with ha } \\
\hline location & context & number of cases \\
\hline \multicolumn{2}{|c|}{ Within the same sentence } & 2 \\
\hline Subject & $\begin{array}{l}\text { company name }+g a \\
\text { company name }+ \text { deha }\end{array}$ & $\begin{array}{l}1 \\
1\end{array}$ \\
\hline \multicolumn{2}{|c|}{ In the previous sentence } & 32 \\
\hline Non-subject & $\begin{array}{l}\text { company name }+ \text { ha } \\
\text { emphasis structure ** } \\
\text { part of the subject * } \\
\text { others }\end{array}$ & $\begin{array}{r}21 \\
5 \\
4 \\
2\end{array}$ \\
\hline \multicolumn{2}{|c|}{ In two sentences before } & 17 \\
\hline Subject & $\begin{array}{l}\text { company name }+h a \\
\text { part of the subject } *\end{array}$ & $\begin{array}{r}16 \\
1\end{array}$ \\
\hline \multicolumn{2}{|c|}{ In three scntences before (in the same paragraph) } & 2 \\
\hline Subject & company name $+h a$ & 2 \\
\hline \multicolumn{2}{|c|}{ In previous paragraph } & 7 \\
\hline Topic of the paragraph & company name + ha & 6 \\
\hline Topic of the paragraph & company name $+y a$ & 1 \\
\hline \multicolumn{2}{|c|}{ In two paragraphs before } & 2 \\
\hline Topic of the paragraph & company name $+h a$ & 2 \\
\hline \multicolumn{2}{|c|}{ In three paragraphs before } & 2 \\
\hline Topic of the paragraph & company name + ha & 2 \\
\hline
\end{tabular}

Note for Table 1 and Table 2

\begin{tabular}{|l|l|}
\hline$*$ & company name referred to is a part of a larger subject noun phrase. \\
\hline$* *$ & $\begin{array}{l}\text { company name referred to comes at the end of the } \\
\text { sentence, a way of emphasising the company name in Japanese. }\end{array}$ \\
\hline$* * *$ & $\begin{array}{l}\text { company name with to (with), kara (from), } \\
\text { wo tsunji (through), tono aidade (between or among). }\end{array}$ \\
\hline
\end{tabular}


for dousha with ga (Table 1), the referred conpany names, or the referents appear in non-subject positions from time to time, especially if the referent appears in the same sentence as dousha does. For dousha with ha (Table 2), compared with Table 1, very few referents are located in the same sentence, and most of the referents are in the subject position. For both occurrences of dousha, a considerable number of the referents appear two or more sentences before, and a few of them show up even two or three paragraphs before.

\section{THREE HEURISTIC METHODS TESTED}

\subsection{Three Heuristic Methods}

One simple and two heuristic methods to find the referents of dousha are described below. 'L'he lirst, the simple method, is to take the closest company nane, (the one which appears most recently before dousha), as its referent (Simple Closest Method or SCM). It is used in this paper to indicate the baseline performance for reference resolution of dousha.

'The second method is a modified Simple Closest Method for dousha with ga. It is basically the same as SCM except that:

- if there is one or more company name in the same sentence before the dousha, take the closest company name as the reforent.

- if there is a company name immediately followed by $h a, g a$, deha, or niyorulo somewhere before dousha, use the closest such company name as the referent.

- if the previous sentence ends with a company name, thus putting an emphasis on the company name, make it the referent.

- if there is a pattern "company name no human name title..." (equivalent to "Litle human name of company name..." in linglish) in the previous sentence, then use the company name as the referent. Typical titles are shachou (president) and kaichou (Chairman of Board).

'The third heuristic method is used for dousha with ha cases. It is also based on SCM except the following points:

- if there is a company name inmediately followed by ha, ga, deha, or niyoruto somewhere before dousha, use the closest such company name as the referent.

- if the previous sentence ends with a company name, thus putting an emphasis on the company name, make it the referent.
- if there is a pattern "company name no human name title..." (equivalent to "title human name of company name..." in Lnglish) in the previous sentence, then use the company name as; the referent.

The third method is in fact a set of the second method, and both of them use semantic information (i.e. company name, human nane, title), syntactic patterns (i.c. where a company name, a human name, or a title appears in a sentence) and several specific lexical items which come immediately after the company names.

\subsection{Test Results}

'The three mothods have been tested on the development data from which the methods were produced and on the set of museen test data.

\subsubsection{Against the dervelopmont data}

As mentioned in section two, there are 42 cases of dousha with ga and 66 cases of dousha with ha.

For the dousha with ga cases, the Simple Closest Method identifies the referents $67 \%$ correctly (27 correct out of 42), and the second method does so $90 \%$ (38 out of 12 ) correctly. SCM misses a number of reforents which appear in previons sentences, and nost of those which appear two or more sentences previously.

lior the cases of dousha with ha, SCM identifies the referents correctly only $52 \%$ ( 34 correct ont of $66)$, however, the third heuristic method correctly identifies $94 \%$ (62 out of 66 ).

\subsubsection{Against the test data}

The test clatia was taken from Japanese newspaper articles on micro-clectronics. 'There are 1078 arti-. cles, and 51 cases of dousha with ga and 250 cases of dousha with ha. 'The test has been conducted against the all ga cases (51 of them) and the first 100 ha cascs.

For the dousha with ga cases, the Simple Closest Method identifies the referents $80 \%$ correctly (41. correct out of 51 ), and the second method does so $96 \%$ ( 49 out of 51 ) correctly.

fior the cases of dousha with ha, SCM identifies; the referents correctly only $83 \%$ (83 correct ont of 100), however, the third heuristic method correctly identifies $96 \%(96$ out of 100$)$.

'The following table, Table 3 , shows the summary of the lest results. 
Table 3 Summary of Test Results

\begin{tabular}{|l|r|r|}
\hline & Development Data & Test Data \\
\hline \multicolumn{3}{|c|}{ dousha with ga } \\
\hline SCM & $67 \%$ & $80 \%$ \\
\hline 2nd method & \multicolumn{3}{|c|}{$90 \%$} & $96 \%$ \\
\hline \multicolumn{3}{|c|}{ dousha with $h a$} \\
\hline SCM & $52 \%$ & $83 \%$ \\
\hline 3rd method & $94 \%$ & $96 \%$ \\
\hline
\end{tabular}

\section{DISCUSSION}

The second and third heuristic methods show high accuracy in finding the referents of dousha with ga and ha. This means that partial semantic parsing (in which key semantic information such as company name, human name, and title is marked) is sufficient for reference resolution of important referential expressions such as dousha in Japanese. Moreover, since the two modified methods are simple, they will be easily implemented by computationally inexpensive finite-state pattern matchers (Hobbs et al. 1992; Cowie et al. 1993). Therefore, they will be suitable for large scale text processing (Jacobs 1992; Chinchor cl al. 1993).

One important point to realize is that the second and third methods, although they are simple to implement, achieve something that is rather complicated and may be computationally expensive otherwise. For example, in order to find the correct referent of a given dousha, you may have to skip one entire paragraph and find the referent two paragraphs before, or you may have to choose the right company name from several possible company names which appear before the given dousha. 'The modified methods do this correctly most of the time without worrying about constructing sometimes complicated syntactic structures of the sentences in the search window for the possible referent.

Another important point is that the modified methods make good use of post-nominal particles, especially $h a$ and $g a$. For example, if the referent is located two sentences or more before, then the referent (the company name) comes with ha almost all the time (35 out of 38 such cases for both dousha). It seems that if the referent of the dousha in consideration is more than a certain distance before, two sentences in this case, then the referent is marked with ha most of the time. Kitani also uses this ha or ga marked company names as key information in his reference resolution algorithm for dousha (Kitani 1994).

\section{CONCLUSION}

The locations and contexts of the referents of dousha in Japanese Joint-Venture articles are determined by hand. Three heuristic methods are proposed and tested. The methods which use semantic information in the text and its patterns show high accuracy in finding the referents (96\% for dousha with $g a$ and $96 \%$ for doush $a$ with $h a$ for the unseen test data). The high success rates suggest that a semantic patternmatching approach is not only a valid method but also an efficient method for reference resolution in the newspaper article domains. Since the Japanese language is highly case-inflected, case (particle) information is used effectively in these methods for reference resolution. How much one can do with semantic pattern matching for reference resolution of similar expressions such as "the company" or "the Japanese company" in English newspaper articles is a topic for future research.

\section{ACKNOWLEDGEMENT}

I would like to thank the Tipster project group at the CRL for their inspiration and suggestions. I would also like to thank Dr. Yorick Wilks, Dr. John Barnden, Mr. Steve Helmreich, and Dr. Jim Cowie for their productive comments. The newspaper articles used in this study are from the Tipster Information Extraction project provided by ARPA.

\section{REFERENCES}

Chinchor, N., I. IIirschman, and D. Lewis (1993). Evaluating Message Understanding Systems: An Analysis of the Third Message Understanding Conference (MUC-3). Computational Linguistics, 19(3), pp. $409-449$

Cowie, J., 'T. Wakao, L. Guthrie, W. Jin, J. Pustejovsky, and S. Waterman (1993). The Diderot Information Extraction System. In the procecdings of The First Conference of the Pacific Association for Computational Linguistics (PACLING 93) Simon Fraser University, Vancouver, B.C. Canada, $p p$. 23-32.

Jacobs, P.S. (1992). Introduction: Text Power and Intelligent Systems. In P.S. Jacobs Ed., Text-Based Intelligent Systems. Lawrence Erlbaum Associates, Ilillsdale New Jersey, $p p$. 1-8.

Ilobbs, J., D. Appelt, M. Tyson, J. Bear, and D. Israel (1992). SRI Interuational Description of the FASTUS System used for MUC-4. In the proceedings of Fourth Message Understanding Conference (MUC4), Morgan Kaufmann Publishers, San Mateo, $p$. 269-275. 
Kitani, 'Г. (1994). Merging Information by Discourse Processing for Information Extraction. In the procecdings of the tenth IEEE Conference on Artificial Intelligence for Applications, pp. 168-173.

Muraki, K., S. Doi, and S. Ando (1993). Contcxt Analysis in Information Lxtraction System based on Keywords and Text Structure. In the proceedings of the f7th National Conference of Information Proccssing Society of Japan, 3-8.. (In Japanese).

Shibata, M., O. Tanaka, and J. Fukumoto (1990). Anaphora in Newspaper Fiditorials. In the proceedings of the 10th National Conference of Information Processing Socicty of Japan, 5F-1. (In Japanese). 